\title{
Comparison of Intravitreal Bevacizumab versus Intravitreal Ranibizumab in Treatment Naive Macular Edema Patients (Real World Evidence in Pakistan)
}

\author{
Hajra Arshad Malik ${ }^{1}$, Rayyan Sabih ${ }^{2}$, Hina Khan ${ }^{3}$, Aamir Asrar $^{4}$, Muhammad Asif $^{5}$ \\ ${ }^{1-4}$ Department of Ophthalmology, Amanat Eye Hospital, Rawalpindi \\ ${ }^{5}$ Departemnt of Public Health, Government College University, Faisalabad
}

\begin{abstract}
Purpose: To compare the short-term efficacy and safety of intraocular Ranibizumab and Bevacizumab in patients with treatment Naïve macular edema.

Study Design: Quasi experimental study.

Place and Duration of Study: Amanat Eye Hospital, from August 2018 to November 2019.

Methods: Patients with macular edema confirmed with optical coherence tomography (OCT) or leakage on fluorescein angiography were included. Patients with NVE, PDR without macular edema and patients who switched to alternative anti-VEGF compounds prior to the completion of three consecutive monthly injections of their respective anti-VEGF or switched to other treatment options were excluded from the study. A thorough clinical examination was conducted including best corrected visual acuity (BCVA, intraocular pressure (IOP), anterior and posterior segment examination and OCT macula. The patients were then allocated to one of the two study arms (either Bevacizumab or Ranibizumab) based on the doctor's input and patient affordability. All patients underwent three consecutive injections of the selected molecule at one month intervals. BCVA, CRT and macular volume were then recorded 04 weeks after the third injection.
\end{abstract}

Results: A statistically significant mean vision gain was observed from baseline in both groups $(p<0.05)$. However, the change in BCVA was not significantly different between intravitreal Bevacizumab group and intravitreal Ranibizumab group $(p>0.05)$. Similarly, although there was improvement in CRT and macular volume in both groups but there was no statistically significant difference between the two.

Conclusions: Treatment with intravitreal Bevacizumab and Ranibizumab injections cause statistically similar anatomical and functional results in cases of treatment naïve macular edema.

Key Words: Bevacizumab, Ranibizumab, Macular Edema, Diabetic Retinopathy, Macular Degeneration, Retinal Vein Occlusion.

How to Cite this Article: Malik HA, Sabih R, Khan H, Asrar A, Asif M. Comparison of Intravitreal Bevacizumab Versus Intravitreal Ranibizumab in Treatment Naïve Macular Edema Patients (Real World Evidence in Pakistan). Pak J Ophthalmol. 2021, 37 (1): 192-197.

Doi: http://doi.org/10.36351/pjo.v37i2.1194

Correspondence: Hajra Arshad Malik

Department of Ophthalmology, Amanat Eye Hospital, Rawalpindi

Email: Hajra.arshad93@gmail.com

Received: January 5, 2021

Accepted: March 5, 2021

\section{INTRODUCTION}

Macular edema can be a potential outcome of a wide array of pathological conditions and represents the final common pathway of a multitude of both intraocular and systemic insults. ${ }^{1,2}$ Common diseases associated with macular edema include diabetic retinopathy (DR), retinal vein occlusion (RVO), 
choroidal neovascularization (CNV), and uveitis. ${ }^{3}$ Vascular endothelial growth factor (VEGF) production is induced by hypoxia and it is a potent endothelial cell angiogenic factor that promotes the growth of new blood vessels and mediates vascular permeability, ultimately contributing to macular edema. ${ }^{4,5}$ In view of this, the introduction of anti-vascular endothelial growth factor (anti-VEGF) injections such as Bevacizumab, Ranibizumab and Aflibercept has revolutionized the treatment of macular edema and is one of the most promising approaches to the management of macular edema and prevention of its possible detrimental effects. ${ }^{6.7}$

While anti-VEGF agents such as Ranibizumab and Aflibercept are FDA (Food and Drug Administration) approved drugs for retinal pathologies including neovascular age-related macular degeneration (nAMD), DR and RVO, ${ }^{8,9}$ Bevacizumab was approved by FDA for the treatment of metastatic colorectal carcinomas, renal carcinomas and glioblastoma multiforme of the brain in 2004. ${ }^{10}$ However, owing to its VEGF inhibiting properties, easy availability and substantially lower cost as opposed to other antiVEGF agents, it is being used off-label for the treatment of nAMD, DR, RVO and iris neovascularization. In fact, the use of Bevacizumab in eye care surpasses that of licensed anti-VEGF drugs especially in the developing countries. ${ }^{11}$

Several trials have been conducted previously to compare the efficacy of Ranibizumab to Bevacizumab. In our study, we prospectively evaluated and compared the efficacy of Ranibizumab and Bevacizumab in patients with various retinal pathologies that warranted anti-VEGF therapy as part of the treatment regimen in a real-world setting in Pakistan.

\section{METHODS}

The study was conducted at Amanat Eye Hospital in Rawalpindi and Islamabad between $1^{\text {st }}$ August 2018 and $1^{\text {st }}$ November 2019. All the cases in this study were between the ages of 33 to 79 years. We recruited 79 eyes of 63 patients with macular edema caused by DR, $\mathrm{RVO}$ and $\mathrm{CNV}$, in which treatment with anti-vascular endothelial growth factor (anti-VEGF) injections was indicated.

Macular edema was confirmed with optical coherence tomography (OCT) or leakage on fluorescein angiography. Exclusion criteria was; patients with NVE (Neovascularization Elsewhere) and PDR (Proliferative Diabetic Retinopathy) with no macular edema, patients who had switched to alternative anti-VEGF compounds prior to the completion of three consecutive monthly injections of their respective anti-VEGF molecules or switched to treatment options other than VEGF inhibitors such as Ozurdex $^{\circledR}$ (dexamethasone intravitreal implant, Allergan, Inc., Irvine, CA) and patients who received any other treatment, including thermal laser photocoagulation, submacular surgery, any other antiVEGF and photodynamic therapy prior to receiving treatment with their respective anti-VEGF.

Ethical approval was obtained from IRB of Amanat Eye Hospital. This study adhered to the tenets of the Declaration of Helsinki and informed written consent was obtained before the investigation began. Clinical record was maintained and it included duration of diabetes, severity, underlying nephropathy and cardiac disease, hyperlipidemias and history of stroke. A thorough clinical examination was conducted including best corrected visual acuity (BCVA). Measurements were converted to logarithm of the minimum angle of resolution [log MAR]). Intraocular pressure, anterior and posterior segment examination and baseline optical coherence tomography (OCT) parameters were recorded, namely central retinal thickness (CRT) and macular volume.

The patients were then allocated to one of the two study arms (either Bevacizumab or Ranibizumab) based on the doctor's input and patient affordability. All patients underwent three consecutive injections of the selected anti-VEGF at one month intervals. BCVA, CRT and macular volume were then recorded 04 weeks after the third injection. If further injections were required on the post operative visit, the patients were counseled and managed accordingly.

The data was analyzed by using SPSS version 23 . The descriptive variables were presented as frequencies, percentages, mean and standard deviation. The continuous data was checked for normality by using Kolmogorov-Smirnov test. As the data was not normally distributed, the non-parametric tests were applied for analysis. The change in BCVA, CRT and macular volume were compared between Intravitreal Bevacizumab group and Intravitreal Ranibizumab group by using Mann-Whitney $U$ test. At $95 \%$ confidence interval, the $\mathrm{p}$ value $<0.05$ was considered as showing statistically significant results. 


\section{RESULTS}

In total, 35 eyes of 29 patients were analyzed who received intravitreal Bevacizumab. The mean age was $59.7 \pm 8.9$ years in this group and were predominantly $14(40 \%)$ males and $21(60 \%)$ females. Twenty six (74.2\%) patients had concomitant co-morbidities, including $20(57.1 \%)$ patients with hypertension, 3 (8.6\%) with hypercholesterolemia, 4 (11.4\%) suffering from nephropathy and $5(14.3 \%)$ from ischemic heart disease. Seven (20\%) patients had glaucoma along with retinal pathology. Mean BCVA (log MAR) at baseline was 1.00 . In addition, the mean CRT at baseline was 492.77 and the mean macular volume at baseline was 11.61 .

In total, 44 eyes of 34 patients received intravitreal Ranibizumab. The patients had a mean age of $58.8 \pm$ 9.4 years. There were $34(77.3 \%)$ males and 10 $(22.7 \%)$ females. Thirty two $(72.7 \%)$ patients had concomitant co-morbidities, including 28 (63.6\%) patients with hypertension, 14 (31.8\%) with hypercholesterolemia, 6 (13.6\%) suffering from nephropathy and 16 (36.4\%) from ischemic heart disease. 16 (36.4\%) patients also had glaucoma accompanying their retinal pathology. Of the 44 treated eyes, $36(81.8 \%)$ exhibited DR with DME, $4(9.1 \%)$ had RVO, and $4(9.1 \%)$ showed evidence of CNV. Mean BCVA (log MAR) at baseline was 0.6. In addition, the mean CRT at baseline was 428.5 and the mean macular volume at baseline was 9.9.

A Mann-Whitney $U$ test was conducted to compare the change in BCVA between Intravitreal Bevacizumab group and Intravitreal Ranibizumab group. With the intravitreal Bevacizumab injection, a statistically significant mean vision gain was observed from baseline as $0.18(\mathrm{p}<0.05)$. The BCVA improved in $17(48.5 \%)$ patients, stabilized in $10(28.6 \%)$ and deteriorated in $8(22.9 \%)$ patients. With intravitreal Ranibizumab, a statistically significant mean vision gain was observed from baseline as $0.34(\mathrm{p}<0.05)$. The BCVA improved in $30(68.2 \%)$ patients, stabilized in $6(13.6 \%)$ and deteriorated in $8(18.2 \%)$ patients. The BCVA significantly improved in either group. However, the change in BCVA was not significantly different between the two groups $(p>0.05)$. It proved that both injections were equally effective in improving visual acuity in cases of macular edema.

With the intravitreal Bevacizumab injection, a statistically significant decrease in CRT was observed
Table 1: Mann-Whitney $U$ test to compare the change in $B C V A$ between intravitreal Avastin $\AA$ injection and intravitreal Patizra ${ }^{\circledR}$ injection.

\begin{tabular}{lccc}
\hline Change in BCVA & $\begin{array}{c}\text { Median } \\
(\text { IQR) }\end{array}$ & $\mathbf{Z}$ & p-value \\
\hline $\begin{array}{l}\text { With third intravitreal } \\
\text { Avastin® injection }\end{array}$ & $0.00 \pm 0.48$ & & \\
$\begin{array}{l}\text { With third intravitreal Patizra }{ }^{\circledR} \\
\text { injection }\end{array}$ & $0.30 \pm 0.68$ & -1.49 & 0.13 \\
\hline
\end{tabular}

from $492.77 \pm 192.31$ at baseline to $362.91 \pm 126.11$ after the third injection ( $\mathrm{p}<0.05)$. With the intravitreal Ranibizumab, a statistically significant decrease in CRT was observed from $428.54 \pm 187.06$ at baseline to $364.50 \pm 170.49$ after the third injection ( $\mathrm{p}<0.05$ ). The reduction in CRT between the two injections was not significantly different as $p>0.05$ (Table 2).

Table 2: Mann-Whitney $U$ test to compare the reduction in CRT between intravitreal Avastin ${ }^{\circledR}$ injection and intravitreal Patizra ${ }^{\circledR}$ injection.

\begin{tabular}{|c|c|c|c|}
\hline $\begin{array}{l}\text { Central Retinal Thickness } \\
\text { Reduction }\end{array}$ & Median (IQR) & $\mathbf{Z}$ & p-value \\
\hline $\begin{array}{l}\text { With third intravitreal } \\
\text { Avastin }{ }^{\circledR} \text { injection }\end{array}$ & $68.00 \pm 178$ & \multirow[b]{2}{*}{-0.27} & \multirow[b]{2}{*}{0.79} \\
\hline $\begin{array}{l}\text { With third intravitreal } \\
\text { Patizra }^{\circledR} \text { injection }\end{array}$ & $66.0 \pm 83.0$ & & \\
\hline
\end{tabular}

Similar results were seen with macular volume in both groups (Table 3).

Table 3: Mann-Whitney $U$ test to compare the reduction in Macular Volume between intravitreal Avastin ${ }^{\circledR}$ injection and intravitreal Patizra ${ }^{\circledR}$ injection.

\begin{tabular}{|c|c|c|c|}
\hline Macular Volume Reduction & $\begin{array}{c}\text { Median } \\
\text { (IQR) }\end{array}$ & $\mathbf{Z}$ & p-value \\
\hline $\begin{array}{l}\text { With third intravitreal } \\
\text { Avastin }{ }^{\circledR} \text { injection } \\
\text { With third intravitreal Patizra }{ }^{\circledR} \\
\text { injection }\end{array}$ & $\begin{array}{l}0.76 \pm 2.08 \\
0.75 \pm 1.29\end{array}$ & -0.51 & 0.61 \\
\hline
\end{tabular}

In the Patizra ${ }^{\circledR}$ group, 168 injections were administered to the patients in total. 30 eyes $(68.2 \%)$ did not require additional injections, because no recurrence of exudation was observed after three consecutive monthly injections of Patizra ${ }^{\circledR}$.

14 eyes $(31.8 \%)$ required additional injections. Among them, 2 eyes required five extra injections, 6 eyes needed 3 more injections, 2 eyes required an 
additional 2 injections, and the remaining 4 eyes needed one extra injection of Patizra ${ }^{\circledR}$.

In the Avastin $^{\circledR}$ group, 131 injections were administered to the patients in total. 27 patients (77.1\%) did not require additional injections, because no recurrence of exudation was observed after three consecutive monthly injections of Avastin ${ }^{\circledR}$.

8 patients (22.9\%) required additional injections. Among them, 1 eye required 6 more injections, 1 required an additional 5 injections, 3 eyes required 3 extra injections, and the remaining 3 eyes needed 2 extra injections of Avastin ${ }^{\circledR}$.

No patient was observed to develop ocular complications, including endophthalmitis, rhegmatogenous retinal detachment, intraocular pressure elevation, cataracts, RPE tears or ocular hemorrhage. In addition, no incidences of systemic side effects including cerebrovascular accident (CVA), myocardial infarction or allergic reactions were noted.

\section{DISCUSSION}

The results of this prospective study establishes that treatment with intravitreal Ranibizumab and Bevacizumab provided clinically and statistically significant improvement in SD-OCT parameters and visual acuity in patients with macular edema secondary to various retinal pathologies in a 'realworld' clinical setting in Pakistan. Ranibizumab and Bevacizumab are both humanized recombinant monoclonal antiVEGF antibodies, though they differ in terms of structure and molecular weight. Bevacizumab is a $149 \mathrm{kD}$ full-length antibody, whereas Ranibizumab is a $49 \mathrm{kD}$ Fab fragment ${ }^{12,13}$ Consequently, they differ substantially in pharmacokinetics such as half-life and retinal penetration. Owing to its smaller molecular size, Ranibizumab enjoys better retinal penetration as opposed to Bevacizumab and is additionally a more potent neutralizer of VEGF. ${ }^{14,15}$ On the other hand, owing to its larger molecular size, Bevacizumab may have a longer half-life and duration of action as opposed to Ranibizumab. A single vial of Bevacizumab can be used to produce multiple doses for intravitreal administration. ${ }^{16}$ The indications as well as the interval between the injections are recommended to be the same for both molecules.

Several studies have been conducted worldwide to establish the efficacy of the intravitreal anti-VEGF agents in various retinal pathologies and to compare their functional and anatomical outcomes. The Diabetic Retinopathy Clinical Research Network (DRCR.net) conducted a multi-center randomized controlled trial to assess the efficacy of anti-VEGF compounds in patients with center involving diabetic macular edema. The DRCR.net Protocol $\mathrm{T}$ results showed a significant improvement in visual acuity from baseline with both Bevacizumab and Ranibizumab and decrease in the central subfield thickness of $101 \pm 121 \mu \mathrm{m}$ and $147 \pm 134 \mu \mathrm{m}$ with Bevacizumab and Ranibizumab respectively at the 1year visit. ${ }^{17}$

Our results are also consistent with the findings of a study conducted on Korean patients with branch retinal vein occlusion (BRVO), which established that both compounds share a similar effectiveness in terms of visual and anatomical outcome as well as retreatment rate. ${ }^{18}$ The mean increase in BCVA was $0.30 \log$ MAR and $0.28 \log$ MAR, and the mean reduction in CRT was $236.7 \mu \mathrm{m}$ and $219.0 \mu \mathrm{m}$ in the Ranibizumab group and the Bevacizumab group respectively. ${ }^{18}$ Similarly, Solomon et al. conducted a systematic review of randomized controlled trials comparing the effectiveness of the two molecules in patients with neovascular age-related macular degeneration and identified no significant difference in the efficacy or safety of the two drugs but a large difference in cost. ${ }^{19}$ Another study by Cai et al. established no apparent differences between the two molecules when treating diabetic macular edema. ${ }^{20}$

A major strength of our study was its prospective study design and the fact that it encompassed most of the common retinal pathologies that lead to macular edema. The analysis was limited, however, by the short follow-up time, relatively small sample size and the fact that it was single-centered. Despite these limitations, our study supports the current data available regarding the comparable short-term effectiveness of intravitreal Ranibizumab and Bevacizumab and proved that they are both equally effective in managing macular edema. Further avenues of research in this direction will include the possibility of a multicenter trial, more extended follow-up and comparison with other anti-VEGF molecules. 


\section{CONCLUSION}

Both Ranibizumab and Bevacizumab are effective for the management of macular edema associated with various retinal pathologies.

\section{Ethical Approval}

The study was approved by the Institutional review board/ Ethical review board. (IRB No. 1910H).

\section{Conflict of Interest}

Authors declared no conflict of interest.

\section{ACKNOWLEDGEMENTS}

The authors are thankful to Mr. Rizwan Waris, the IT manager and ophthalmic photographer at Amanat Eye Hospital, for his assistance in conducting OCT scans and in data collection.

\section{REFERENCES}

1. Johnson MW. Etiology and Treatment of Macular Edema. Am J Ophthalmol. 2009; 147 (1): 11-21.

2. Tranos PG, Wickremasinghe SS, Stangos NT, Topouzis F, Tsinopoulos I, Pavesio CE. Macular edema. Surv Ophthalmol. 2004; 49 (5): 470-490.

3. Rotsos TG, Moschos MM. Cystoid macular edema. Clin Ophthalmol. 2008; 2 (4): 919-930.

4. Yorston D. Anti-VEGF drugs in the prevention of blindness. Comm Eye Health, 2014; 27 (87): 44-46.

5. Kaya M, Karahan E, Ozturk T, Kocak N, Kaynak S. Effectiveness of Intravitreal Ranibizumab for Diabetic Macular Edema with Serous Retinal Detachment. Korean J Ophthalmol. 2018; 32 (4): 296-302.

6. Sacconi R, Giuffrè C, Corbelli E, Borrelli E, Querques G, Bandello F. Emerging therapies in the management of macular edema: a review. F1000 Res. 2019 Aug 12; 8: F1000 Faculty Rev-1413.

Doi: 10.12688/f1000research.19198.

7. Wykoff CC, Clark WL, Nielsen JS, Brill JV, Greene LS, Heggen CL. Optimizing Anti-VEGF Treatment Outcomes for Patients with Neovascular Age-Related Macular Degeneration. J Manag Care Spec Pharm. 2018; 24 (2-a Suppl): S3-S15.

8. Mansour AM, Al-Ghadban SI, Yunis MH, ElSabban ME. Ziv-aflibercept in macular disease. Br J Ophthalmol. 2015; 99 (8): 1055-1059.

9. Malik D, Tarek M, Caceres del Carpio J, Ramirez C, Boyer D, Kenney MC, et al. Safety profiles of antiVEGF drugs: bevacizumab, ranibizumab, aflibercept and ziv-aflibercept on human retinal pigment epithelium cells in culture. Br J Ophthalmol. 2014; 98 (Suppl 1): i11-i16.
10. Akiyode O, Dunkelly-Allen N. Ranibizumab: A Review of Its Use in the Treatment of Diabetic Retinopathy in Patients with Diabetic Macular Edema. J Pharm Technol. 2016; 32 (1): 22-28.

11. Jan S, Nazim M, Karim S, Hussain Z. Intravitreal Bevacizumab: Indications and Complications. J Ayub Med Coll Abbottabad. 2016; 28 (2): 364-368.

12. Bakri SJ, Snyder MR, Reid JM, Pulido JS, Singh RJ. Pharmacokinetics of intravitreal bevacizumab (Avastin). Ophthalmology, 2007; 114 (5): 855-859.

13. Bakri SJ, Snyder MR, Reid JM, Pulido JS, Ezzat MK, Singh RJ. Pharmacokinetics of Intravitreal Ranibizumab (Lucentis). Ophthalmology, 2007; 114 (12): 2179-2182.

14. Terasaki H, Sakamoto T, Shirasawa M, Yoshihara $\mathbf{N}$, Otsuka H, Sonoda $\mathrm{S}$, et al. Penetration of bevacizumab and ranibizumab through retinal pigment epithelial layer in vitro. Retina. 2015; 35 (5): 10071015.

15. Yu L, Liang XH, Ferrara N. Comparing protein VEGF inhibitors: In vitro biological studies. Biochem Biophys Res Commun. 2011; 408 (2): 276-281.

16. Poku E, Rathbone J, Wong R, Everson-Hock E, Essat M, Pandor A, et al. The safety of intravitreal bevacizumab monotherapy in adult ophthalmic conditions: Systematic review. BMJ Open, 2014; 4: e005244.

17. Wells JA, Glassman AR, Ayala AR, Jampol LM, Aiello LP, Antoszyk AN, et al. Aflibercept, bevacizumab, or ranibizumab for diabetic macular edema. N Engl J Med. 2015; 372 (13): 1193-1203.

18. Son BK, Kwak HW, Kim ES, Yu SY. Comparison of Ranibizumab and Bevacizumab for Macular Edema Associated with Branch Retinal Vein Occlusion. Korean J Ophthalmol. 2017; 31 (3): 209-216.

19. Solomon SD, Lindsley KB, Krzystolik MG, Vedula SS, Hawkins BS. Intravitreal Bevacizumab Versus Ranibizumab for Treatment of Neovascular AgeRelated Macular Degeneration: Findings from a Cochrane Systematic Review. Ophthalmology, 2016; 123 (1): 70-77.

20. Cai S, Bressler NM. Aflibercept, bevacizumab or ranibizumab for diabetic macular oedema: Recent clinically relevant findings from DRCR.net Protocol T. Curr Opin Ophthalmol. 2017; 28 (6): 636-643.

\section{Authors' Designation and Contribution}

Hajra Arshad Malik; Research Assistant: Concepts, Design, Literature search, Data acquisition, Manuscript preparation, Manuscript editing.

Rayyan Sabih; Research Assistant: Concepts, Design, Literature search, Data acquisition, Manuscript preparation, Manuscript editing. 
Hina Khan; Research Assistant: Concepts, Design, Literature search, Data acquisition, Manuscript preparation, Manuscript editing, Manuscript review.

Aamir Asrar; Consultant Ophthalmologist: Concepts, Design, Literature search, Data acquisition, Manuscript preparation, Manuscript editing, Manuscript review.
Muhammad Asif; Lecturer: Concepts, Design, Literature search, Data analysis, Statistical analysis, Manuscript preparation, Manuscript editing, Manuscript review.

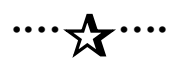

